\title{
Comparison of epidural technique with combined spinal epidural technique for labor analgesia
}

\author{
Dhaval Kumar C. Patel ${ }^{1}$, Neeta Abhay Kavishvar ${ }^{2, *}$ \\ ${ }^{1}$ Assistant Professor, ${ }^{2}$ Professor \& HOD, Dept. of Anaesthesia, Government Medical College, Surat, Gujarat, India \\ *Corresponding Author: \\ Email: dcp991717@gmail.com
}

Received: $12^{\text {th }}$ August, 2017

Accepted: $07^{\text {th }}$ September, 2017

\begin{abstract}
Introduction: For pain relief during labor, regional analgesia is considered the most preferred technique; nevertheless the best method is yet to be determined. We carried out a randomized study to assess efficacy, safety \& maternal satisfaction with standard epidural and combined spinal epidural (CSE) analgesia technique among 40 primigarvida.

Materials and Methods: Healthy primigarvida in labor having cervical dilatation between 3 to $5 \mathrm{~cm}$ were assigned randomly to receive either epidural or CSE for labor analgesia. Analgesia was established in Epidural group with $12 \mathrm{ml}$ of $0.0625 \%$ bupivacaine added with $2 \mu \mathrm{g} / \mathrm{ml}$ fentanyl \& in CSE group with intrathecal injection of $2.5 \mathrm{mg} 0.5 \%$ heavy bupivacaine plus fentanyl $25 \mu \mathrm{g}$ (total $2 \mathrm{ml}$ ). In both groups whenever patient's VAS $>3,2^{\text {nd }}$ dose was given in form of epidural bolus $10 \mathrm{ml}$ $0.0625 \%$ bupivacaine $+2 \mu \mathrm{g} / \mathrm{ml}$ fentanyl, followed by infusion of same concentration at $8 \mathrm{ml} / \mathrm{h}$.

Results: The onset of labor analgesia was significantly faster in CSE group $(5.5 \pm 1.9$ vs. $13 \pm 5.9$ minutes, $p<0.001)$ compared to epidural group. More than $75 \%$ patients in both groups didn't developed any motor blockade. The total dose of bupivacaine used in Epidural group was $20.5 \pm 6.6 \mathrm{mg}$ whereas it was only $8.5 \pm 7.7 \mathrm{mg}$ in CSE group which was significant low than epidural group; same was for fentanyl $(65.1 \pm 21.6 \mu \mathrm{g}$ in epidural and $44.4 \pm 24.6 \mu \mathrm{g}$ in CSE group). In CSE group $35 \%$ patients had pruritus and $10 \%$ had nausea and vomiting, but none had in epidural group. Mothers have labeled quality of analgesia comparable.

Conclusions: Both techniques were equally effective in relieving the pain during labor, but the onset of analgesia with CSE technique was faster than epidural group. The LSCS rate was comparable and complications were minor. Thus CSE can be safe and effective alternative to standard epidural technique for labor analgesia.
\end{abstract}

Keywords: Bupivacaine, Combined spinal epidural, Epidural, Fentanyl, Intrathecal, Labor analgesia.

\section{Introduction}

Pain relief in labor has been surrounded with lots of myths and controversies. The pain experienced during labor has multiple physiological and psychosocial dimensions and the perception of pain varies from one woman to another. It's an ongoing challenge to provide effective and safe analgesia during labor. There is increase in knowledge and understanding of physiology and pharmacotherapy of labor pain. The training in obstetric anaesthesia has improved, which has played important role in improving the quality of labor analgesia.

Pain is a noxious and unpleasant stimulus which produces fear and anxiety. Patient hyperventilates during contraction of the uterus, which increases the work of breathing and oxygen consumption. Unrelieved stress in labor increases plasma cortisol and catecholamine concentration which reduces uteroplacental blood flow by $35-70 \%$ compounding the effects of hyperventilation on the oxygen supply to the fetus.

The ideal obstetric analgesic technique should be able to provide effective pain relief with minimal side effects for both mother and baby \& it should not affect the progress of labor. The neuraxial technique was introduced in the 1950s for pain relief in labor. Epidural analgesia technique for labor analgesia has been used extensively but it has drawbacks like delayed onset and motor blockade. Recent trend of using local anaesthetic in very low concentration along with opioid could overcome the drawback of motor blockade but slow onset is still a matter of concern. Fast onset with subarachnoid block is known. With CSE technique this property can be used for labor analgesia.

This study was planned to compare two different techniques. The primary aim of study was to evaluate onset of labor analgesia and total dose of bupivacaine and fentanyl consumed in epidural analgesia group and CSE analgesia group. The secondary aims were to observe the mode of delivery, incidence of complications and acceptability of both techniques to the parturients.

\section{Materials and Methods}

After receiving permission from Institutional Review Board the study was conducted in a tertiary care hospital during 2013-14. The inclusion criteria was a nullipara or primigravida of age between 18 to 35 years of American Society of Anaesthesiologists class 1 or 2 physical status who were in active phase of labor with cervical dilatation three to five $\mathrm{cm}$ having single fetus with vertex presentation. Patients with complicated obstetric history and contraindications to regional analgesia were excluded from the study. 
Patients who had fulfilled the inclusion criteria and wanted or willing for labor analgesia were enrolled for the study. Patients were randomly divided in either epidural group or CSE group comprising of 20 patients in each group.

After explaining the procedure written consent was taken from patient and relative. Intravenous access was secured and $500 \mathrm{ml}$ of ringer lactate was started for preloading. Patients were pre-medicated with inj glycopyrolate $0.2 \mathrm{mg}$ i.v and inj ondansatron four $\mathrm{mg}$ iv. Pre procedure pulse, blood-pressure, VAS score, fetal heart rate and obstetric parameters like cervical dilatation, station, and effacement were noted. Patients were placed in the left lateral position. Under aseptic precaution, touhy needle $18 \mathrm{G}$ was inserted at L3-L4 inter-spinous space and epidural space was identified with loss of resistance technique.

In epidural group E catheter was fixed and patient was turned supine. A test dose of $2 \mathrm{ml}$ of $2 \%$ lignocaine with adrenaline 1:2 lac was given through epidural catheter to exclude intravascular or intrathecal placement. After negative test dose, in epidural group E first dose was given in form of $12 \mathrm{ml}$ of $0.0625 \%$ bupivacaine with $2 \mu \mathrm{g} / \mathrm{ml}$ fentanyl.

In CSE group $C$ after epidural catheter insertion the intrathecal space was located one space lower to epidural catheter insertion, by $25 \mathrm{G}$ spinal needle. The first dose in this group was $2.5 \mathrm{mg} 0.5 \%$ heavy bupivacaine + fentanyl $25 \mu \mathrm{g}+1 \mathrm{ml}$ normal saline in intrathecal space. Epidural catheter was fixed and patient was turned supine.

All patients were monitored for pulse, systolic blood pressure, sensory effects, motor effect, VAS score at $2 \mathrm{~min}, 5 \mathrm{~min} 10 \mathrm{~min}, 15 \mathrm{~min}, 20 \mathrm{~min}, 30 \mathrm{~min}$, $45 \mathrm{~min}, 60 \mathrm{~min}, 90 \mathrm{~min}, 120 \mathrm{~min}, 150 \mathrm{~min}$, till delivery. Fetal heart rate was monitored intermittently by anaesthesiologist and obstetrician with stethoscope and cardio tocography machine. Analgesia was assessed using ten points visual analogue scale (VAS). Motor blockade was assessed with Modified Bromage Scale. In both group when patient complained of pain and VAS $>3$, analgesia was supplemented with epidural dose of $10 \mathrm{ml} 0.0625 \%$ bupivacaine $+2 \mu \mathrm{g} / \mathrm{ml}$ fentanyl, followed by infusion of $0.0625 \%$ bupivacaine $+2 \mu \mathrm{g}$ fentanyl $(8 \mathrm{ml} / \mathrm{h})$.

In CSE group test dose was given before supplementing epidural analgesia. Any time during the infusion if patient complained of pain and VAS score was more than three then rescue analgesia with $5 \mathrm{ml}$ of the above prepared solution was given.

Onset of labor analgesia, duration analgesia and total duration between initiation of labor analgesia and delivery were recorded. The total dose of bupivacaine in $\mathrm{mg}$ and fentanyl in $\mu \mathrm{g}$ consumed in each patient were calculated. The observations were noted till normal or assisted delivery, or the decision is made to perform a caesarean delivery. The mode of delivery, neonatal APGAR sore and side effects during labor analgesia were noted. The epidural catheter was removed after delivery. All mothers were asked about their satisfaction regarding the quality of labor analgesia.

In this study, results were presented as mean \pm SD for quantitative data. For comparison between groups un-paired ' $\mathrm{t}$ ' test and for qualitative data chi square test was applied. Difference was considered statistically significant if ' $p$ ' value was less than 0.05 . Microsoft excel was used for mean \& S.D calculation \& open EPI software for calculation of $P$ value. The primary aim of the study was to compare the onset of labor analgesia of CSE technique with epidural technique. The power of study was calculated considering the onset of analgesia and it was $99.97 \%$.

\section{Results}

Table 1: Demographic Data

\begin{tabular}{|l|c|c|c|}
\hline & Group E $(\mathbf{n}=\mathbf{2 0})$ & Group C $(\mathbf{n}=\mathbf{2 0})$ & $*$ * V Value \\
\cline { 2 - 4 } & Epidural & CSE & \\
\hline Age $(\mathrm{yr})$ & $20.9 \pm 3.0$ & $21.1 \pm 3.2$ & $0.8(\mathrm{NS})$ \\
\hline Weight $(\mathrm{kg})$ & $50.7 \pm 3.1$ & $51.1 \pm 3.2$ & $0.6(\mathrm{NS})$ \\
\hline Height $(\mathrm{cm})$ & $148.9 \pm 2.8$ & $152.9 \pm 2.7$ & $0.8(\mathrm{NS})$ \\
\hline Cervical dilatation $(\mathrm{cm})$ & $4.1 \pm 0.4$ & $4.1 \pm 0.3$ & $0.7(\mathrm{NS})$ \\
\hline Effacement $(\%)$ & $45.5 \pm 5.1$ & $46.0 \pm 5.0$ & $0.7(\mathrm{NS})$ \\
\hline
\end{tabular}

Data are presented as mean $\pm \mathrm{SD}$. *Student's unpaired $\mathrm{t}$ test, $\mathrm{P}$ value $<0.05 \mathrm{~S}$ (significant), $\mathrm{P}>0.05 \mathrm{NS}$ (not significant)

The youngest parturient was 18 years old and the oldest one was 26 years old. The cervical dilatation was $4.1 \pm 0.4 \mathrm{~cm}$ and $4.1 \pm 0.3 \mathrm{~cm}$ in both groups with $45-46 \%$ effacement of cervix. This matches with the criteria for enrolling the parturient for labor analgesia in both the groups. 
Table 2: Mean Duration for Onset of Analgesia

\begin{tabular}{|l|c|c|c|}
\hline & Group E (EPI) & Group C (CSE) & p Value \\
\hline Onset of analgesia (min) & $13 \pm 5.9$ & $5.5 \pm 1.9$ & $\mathrm{p}<0.001(\mathrm{~S})$ \\
\hline
\end{tabular}

Data are presented as mean $\pm \mathrm{SD}$. Student's unpaired $\mathrm{t}$ test, $\mathrm{P}$ value $<0.05 \mathrm{~S}$ (significant), $\mathrm{P}>0.05 \mathrm{NS}$ (not significant)

In group CSE 70\% patient could achieve VAS $<3$ within five minutes of initiation of analgesia whereas it was in only 5\% patient in epidural group. Thus the onset of analgesia was significantly faster $(\mathrm{p}<0.001)$ in CSE group than in epidural group.

Table 3: Mode of Delivery

\begin{tabular}{|l|l|c|c|c|c|c|}
\hline S. N. & Mode of & Group E & & Group C & & $*$ P value \\
\cline { 3 - 7 } & Delivery & $(\mathrm{N}=20)$ & $\%$ & $(\mathrm{~N}=20)$ & $\%$ & \\
\hline 1 & Spontaneous & 16 & $80 \%$ & 16 & $80 \%$ & 0.6 \\
\hline 2 & Instrumental & 1 & $5 \%$ & 3 & $15 \%$ & 0.5 \\
\hline 3 & LSCS & 3 & $15 \%$ & 1 & $5 \%$ & 0.5 \\
\hline & Total & 20 & $100 \%$ & 20 & $100 \%$ & \\
\hline
\end{tabular}

*Chi Square test (after Yates' correction), $\mathrm{P}$ value $<0.05 \mathrm{~S}$ (significant), $\mathrm{P}>0.05 \mathrm{NS}$ (not significant)

In both group $80 \%$ patients delivered vaginally. In epidural group three patients required LSCS where in CSE group one patient required LSCS. One patient in group E and three patients in group C were delivered with the help of vacuum/forceps. The difference was statistically not significant ( $\mathrm{p}$ value $>0.05$ ). The average duration of labor after initiation of labor analgesia was $194 \pm 63.9$ minutes in Group E and $150 \pm 63.8$ minutes in group CSE $(\mathrm{P}<0.05)$. This indicated that duration of labor was shorter in CSE group than epidural group.

Table 4: Mean Total Dose of Bupivacaine and Fentanyl

\begin{tabular}{|l|l|c|c|c|}
\hline No & Total doses of Drugs & $\begin{array}{c}\text { Group E } \\
(\mathbf{n = 1 7} *)\end{array}$ & $\begin{array}{c}\text { Group C } \\
(\mathbf{n = 1 9} \dagger)\end{array}$ & P Value \\
\hline 1 & Total dose of bupivacaine $(\mathrm{mg})$ & $20.5 \pm 6.6$ & $8.5 \pm 7.7$ & $0.00019(\mathrm{~s})$ \\
\hline 2 & Total dose of fentanyl $(\mu \mathrm{g})$ & $65.1 \pm 21.6$ & $44.4 \pm 24.6$ & $0.011(\mathrm{~s})$ \\
\hline
\end{tabular}

Student's unpaired t test, $\mathrm{P}$ value $<0.05 \mathrm{~S}$ (significant), $\mathrm{P}>0.05 \mathrm{NS}$ (not significant).

The data of $* 3$ patients in epidural group and $\dagger 1$ patient from CSE group were excluded from analysis as they require LSCS.

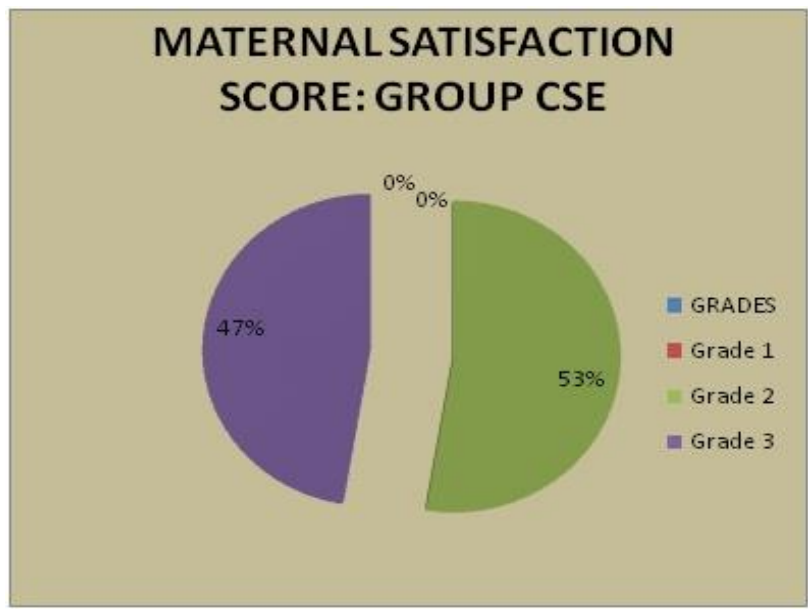

Fig. 1: Maternal satisfaction score CSE 


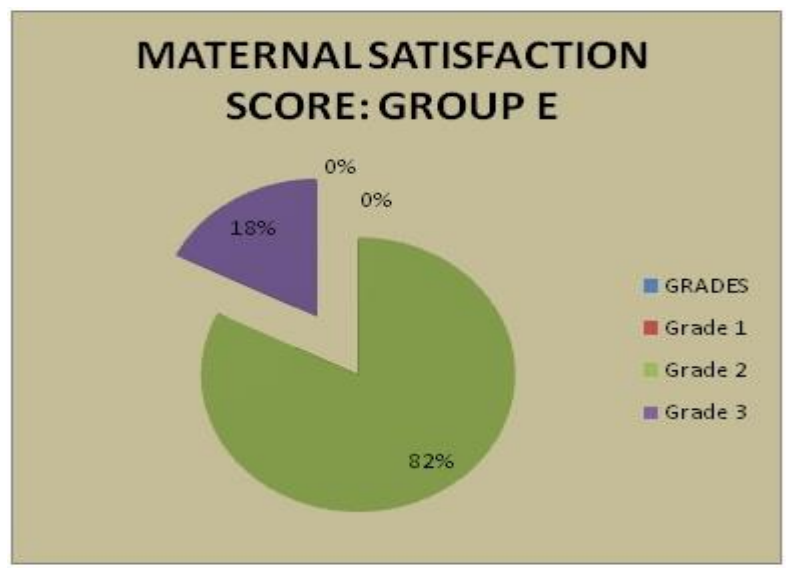

Fig. 2: Maternal satisfaction score Epidural

\section{Discussion}

It is well known that regional technique of labor analgesia has advantages like no risk of gastric aspiration, avoids use of sedative drugs and allows mother to remain awake and participate in the process of child birth. It also helps in early initiation of breast feeding and mother-child bonding. Epidural and CSE are the most effective techniques, though these techniques require skill, experience, special gadgets and drugs.

If the recruited population in both groups is comparable then only the quality of analgesia can be compared. To avoid this incongruity only primigravida and nullipara were included in both groups.

Initiation of labor analgesia in early stage (latent phase) is associated with longer duration of labor, more operative intervention, and increased cost. Whereas labor analgesia initiated in late stage (advanced period) make patient to suffer intense pain of active labor which will not fulfil the idea of labor analgesia. So labor analgesia was commended in parturients with active labor pain and cervical dilatation of 3 to $5 \mathrm{~cm}$.

Onset of analgesia has been defined by various authors as: time taken for achieving a verbal rating score of three or four, time taken for 50\% reduction in VAS score or time taken to achieve a dermatome level of T8. In this study, time of onset of analgesia was taken when VAS score was less than three (VAS $<3$ ). In present study $70 \%$ patients from group CSE had VAS $<3$ within $0-5$ minutes whereas only $5 \%$ patients achieved VAS $<3$ in epidural group E. One patient in epidural group took almost 30 minute for adequate pain relief. The average onset of analgesia was $13 \pm 5.9$ minutes in epidural group and $5.5 \pm 1.9$ minutes in CSE group. $(\mathrm{P}<0.05)$.

AbdElBarr et al. ${ }^{10}$ studied total 100 parturients in which it was noted that onset of analgesia (time to reach T10 level of sensory block) was shorter in CSE group (8.3 \pm 2.0 minutes) in compared to epidural group (12.4 \pm 5.7 minutes). Pulse rate and systolic blood pressure were comparable between two groups during labor analgesia.
In this study not a single patient in either group had grade three or grade two motor blocks. Total 10\% patients in epidural group and $25 \%$ patients in CSE group had grade one motor block which lasted for only 20-30 minutes in epidural group and maximum up to 50 min in CSE group.

Differential block is gradual and sequential block of different types of nerve fibres when exposed to local anaesthetic. Small fibres are more susceptible to block than large nerve fibres and lower concentration of local anaesthetic will block only small fibres and not large fibres. The local anaesthetic concentration used for maintenance of labor analgesia in both group was very low almost $0.0625 \%$. So the motor blockage was minimal in both groups. In CSE group $2.5 \mathrm{mg}$ bupivacaine was used in $2 \mathrm{ml}$ for intrathecal component had produced some motor blockage but not lasted for more than half hours.

The duration of labor after initiation of labor analgesia was noted significantly shorter in CSE group than epidural group. Tsen et al. ${ }^{5}$ in 1999 had also noted that CSE is associated with more rapid cervical dilatation. It was postulated by them that rapid onset of analgesia with CSE technique decreases maternal epinephrine level. They mentioned that maternal epinephrine has tocolytic effect. Initiation of labor analgesia reducing maternal epinephrine stimulates uterine contraction and facilitates progress of labor.

Total dose of bupivacaine was $20.5 \pm 6.6 \mathrm{mg}$ in epidural group and $8.5 \pm 7.7 \mathrm{mg}$ in CSE group. The total dose of fentanyl was $65.1 \pm 21.6 \mu \mathrm{g}$ in epidural group whereas $44.4 \pm 24.6 \mu \mathrm{g}$ in CSE group. Total 11 patients delivered under spinal analgesia that means they required minimal bupivacaine and fentanyl for the labor analgesia. Thus reduction in dose of local anaesthetic in CSE group can be beneficial for uterine activity as well as the fetus. Pain causing maternal hyperventilationhypoventilation sequence is responsible for more local anaesthetic delivery to fetus. Labor analgesia can decrease this and CSE by further reducing total dose of local anaesthetic and opioid enhances safety of mother 
and baby. APGAR score was normal in all the patients in both the groups.

Labor analgesia was graded as good by $82 \%$ mothers in Group E whereas 52\% in Group CSE. Seventeen percentage mothers in Group E and $47 \%$ in Group CSE graded as excellent. Colllis et al. ${ }^{4}$ compared CSE with epidural; they concluded that women prefer CSE over epidural labor analgesia perhaps due to fast onset and less motor block whereas Simmons et al. ${ }^{11}$ noted that there was no significant difference in maternal satisfaction level in CSE or epidural analgesia group. There was no complication in epidural group. Pruritus was seen in $35 \%$ patients in CSE group. Nausea or vomiting was observed in $10 \%$, high block in $25 \%$ and hypotension in 5\% patients with CSE technique of labor analgesia. The number of patients included in this study was forty. So, before generalising the results, further study with more patients is required. The further study can focus on progress of labor and mode of delivery.

Thus, it was concluded that though the onset of analgesia with CSE technique is faster, both Epidural and CSE technique are equally effective in relieving the pain during labor. Total dose of local anaesthetic and opioid used during CSE analgesia was lesser than epidural labor analgesia. Both techniques were not associated with significant complications except few incidences like pruritis and nausea-vomiting in CSE group. So CSE can be considered as safe and effective alternative to epidural labor analgesia especially when rapid onset is required.

\section{References}

1. Devid BJ. Anaesthesia for obstetrics. In: Miller RD, editor. Text Book Of Miller's Anaesthesia,7th ed. Philadelphia: Churchil living stone; 2010. p. 2203-40.

2. Devid LB. Spinal, epidural and caudal anesthesia. In:Miller RD, editor. Text Book Of Miller's

Anaesthesia,b7th ed. Philadelphia: Churchil living stone; 2010. p.1611-34.

3. Chestnut DH, Owen CL, Bates JN, Ostman LG, Choi WW, Geiger MW Continuous infusion epidural analgesia during labor, a randomized double-blind comparison of $0.0625 \%$ bupivacaine $/ 0.0002 \%$ fentanyl versus $0.125 \%$ bupivacaine. Anesthesiology 1988; 68:754-9.

4. Collis Re, David Dwl, Avelling W. Randomised comparison of combined spinal-epidural and standard epidural analgesia during labor. Lancet 1995;345:1413-6.

5. Tsen LC, Thue B, Datta S, Segall S Is combined spinalepidural analgesia associated with more rapid cervical dilation in nulliparous patients when compared with conventional epidural analgesia? Anesthesiology 1999;91:920-5.

6. Norris MC, Grieco WM, Borkowski M, Leighton BL, Arkoosh VA, Huffnagle HJ, et al. Complications of labor analgesia: epidural versus combined spinal epidural techniques. Anesth Analg 1994;79:529-37.

7. Miro M, Guasch E, Gilsanz F. Comparison of epidural analgesia with combined spinal-epidural analgesia for labor: a retrospective study of 6497 cases. Int J Obstet Anesth 2008;17:15-9.
8. Norris MC, Fogel ST, Conway-Long C. Combined spinal-epidural versus epidural labor analgesia. Anesthesiology 2001;95:913-20.

9. Stoelting Robert K Hiller, Simmon C. Pharmacology and physiology in anesthetic practice. 4th ed. Philadelphia:Lippincott Williams and Wilkins. 2006. P.182-9.

10. AbdElBarr T, Elshalakany NA, Shafik YM. Single dose spinal analgesia: Is it a good alternative to epidural analgesia in controlling labor pain? Egyptian Military Medical Academy 2013;13:241-6.

11. Simmons SW, Taghizadeh N, Dennis AT, Hughes D, Cyna AM:Combined spinal-epidural versus epidural analgesia in labour (Review) The Cochrane Collaboration and published in The Cochrane Library 2012;10:21-30. 